\title{
EQ-5D visual analog scale and utility index values in individuals with diabetes and at risk for diabetes: Findings from the Study to Help Improve Early evaluation and management of risk factors Leading to Diabetes (SHIELD)
}

\author{
Susan Grandy ${ }^{1}$ and Kathleen M Fox*2
}

Address: ${ }^{1}$ Health Economics and Outcomes Research, AstraZeneca Pharmaceuticals LP, Wilmington, DE, USA and ${ }^{2}$ Strategic Healthcare Solutions, LLC, Monkton, MD, USA

Email: Susan Grandy - susan.grandy@astrazeneca.com; Kathleen M Fox* - kathyfox@ comcast.net

* Corresponding author

Published: 27 February 2008

Health and Quality of Life Outcomes 2008, 6:18 doi:10.1186/1477-7525-6-18

This article is available from: http://www.hqlo.com/content/6/1//8

(c) 2008 Grandy and Fox; licensee BioMed Central Ltd.

This is an Open Access article distributed under the terms of the Creative Commons Attribution License (http://creativecommons.org/licenses/by/2.0), which permits unrestricted use, distribution, and reproduction in any medium, provided the original work is properly cited.
Received: 14 August 2007

Accepted: 27 February 2008

\begin{abstract}
Background: The EQ-5D was used to compare burden experienced by respondents with diabetes and those at risk for diabetes.

Methods: A survey including the EQ-5D was mailed to individuals with self-reported diabetes, as well as those without diabetes but with the following risk factors (RFs): (I) abdominal obesity, (2) body mass index $\geq 28 \mathrm{~kg} / \mathrm{m}^{2}$, (3) dyslipidemia, (4) hypertension, and (5) cardiovascular disease. Non-diabetes respondents were combined into 0-2 RFs and 3-5 RFs. Mean EQ-5D scores were compared across groups using analysis of variance. Multivariable linear regression modeling identified factors affecting respondents' EQ-5D scores.
\end{abstract}

Results: Complete responses were available from $>75 \%$ of each cohort. Mean EQ-5D index scores were significantly lower for respondents with type 2 diabetes and 3-5 RFs $(0.778$ and 0.792 , respectively) than for those with $0-2$ RFs $(0.870, p<0.00$ I for each); score for respondents with type 2 diabetes was also significantly lower than for those with 3-5 RFs $(p<0.00 I)$. Similar patterns were seen for visual analog scale (VAS). For both VAS and index scores, after adjusting for other characteristics, respondents reported decreasing EQ-5D scores as status moved from low to high risk ( -6.49 for VAS score and -0.045 for index score) to a diagnosis of type 2 diabetes $(-9.75$ for VAS score and -0.054 for index score; $p<0.001$ vs. $0-2$ RFs for all).

Conclusion: High-risk and type 2 diabetes groups had similar EQ-5D scores, and both were substantially lower than in low-risk respondents.

\section{Introduction}

It has been estimated that diabetes mellitus affects approximately 21 million people in the U.S. [1]. Complications from diabetes include blindness, kidney disease, nerve damage, arterial disease, abnormal cholesterol lev- els, hypertension, heart disease, and stroke. Heart disease and stroke account for $65 \%$ of deaths in patients with diabetes, with a death rate 2-4 times higher than in adults without diabetes [2]. Diabetes is the fifth leading cause of mortality in the U.S., and is associated with increasing 
economic burden, estimated at $\$ 132$ billion in 2002, up from $\$ 98$ billion in 1997 [3].

Diabetes and its complications and comorbidities substantially affect patients' health-related quality of life (HRQoL) [4-7]. The impact of treatment, complications, and comorbidities has been documented to adversely affect HRQoL among individuals with type 2 diabetes mellitus [8]. Yet, there is little information on HRQoL among individuals who do not have diabetes but are at risk for diabetes. While several disease-specific instruments have been used to measure the HRQoL of patients with diabetes, there is a need for generic HRQoL measures as well, to allow comparisons with populations without diabetes. In particular, such measures can be used to compare the incremental burden experienced by patients with diabetes and those without diabetes but with similar comorbidities and risk factors.

A frequently used generic HRQoL instrument is the EuroQoL EQ-5D [9]. The objective of this investigation was to compare EQ-5D scores of individuals diagnosed with diabetes and those with varying levels of cardiometabolic risk, using data from the Study to Help Improve Early evaluation and management of risk factors Leading to Diabetes (SHIELD). This investigation will ascertain whether the burden of having risk factors for diabetes impacts HRQoL in a similar way as having diabetes. SHIELD is a 5-year longitudinal survey-based study that is being conducted to better understand the overall burden of illness of people living with diabetes as well as those at risk for its development.

\section{Methods}

A 12-item general population screening questionnaire was used to identify individuals with a diagnosis of diabetes and those with risk factors associated with a diagnosis of diabetes. In 2004, the screening survey was mailed to a stratified random sample of 200,000 U.S. households [10]. This was followed by a baseline survey in which a sample of identified cases were followed up with a more detailed survey assessing each individual's health status, health knowledge and attitudes, and current healthrelated behaviors and treatments. A total of 22,001 baseline survey questionnaires were mailed in late 2004. Respondents freely volunteered to complete the survey without enticement, and no IRB approval was required.

\section{Risk factors}

In addition to self-reported diagnosis of diabetes, responses to the screening questionnaire were used to identify respondents with the following risk factors: (1) abdominal obesity (waist circumference: men $>97 \mathrm{~cm}$, women $>89 \mathrm{~cm}$ ), (2) body mass index (BMI) $\geq 28 \mathrm{~kg} / \mathrm{m}^{2}$, (3) dyslipidemia (reported diagnosis of cholesterol prob- lems of any type), (4) hypertension (reported diagnosis of high blood pressure), and (5) history of cardiovascular disease (reported heart disease/myocardial infarction, narrow or blocked arteries, stroke, coronary artery bypass graft surgery, angioplasty, stents, and/or surgery to clear arteries). These risk factors were derived from the literature, national guidelines, and expert opinion as modifiable or treatable risk factors for the future development and/or diagnosis of diabetes $[11,12]$. Respondents with $0-2$ risk factors were classified as low risk and those with 3-5 risk factors were grouped as high risk for a diagnosis of diabetes. This paper will focus on respondents with type 2 diabetes, low risk (0-2 risk factors), and high risk (3-5 risk factors).

\section{EQ-5D}

The EQ-5D was used as a measure of respondents' HRQoL and utility values. The EQ-5D provides a simple descriptive profile and a single index value for health status $[9,13]$. The EQ-5D self-reported questionnaire includes a visual analog scale (VAS), which records the respondent's self-rated health status on a graduated (0-100) scale, with higher scores for higher HRQoL. It also includes the EQ5D descriptive system, which comprises 5 dimensions of health: mobility, self-care, usual activities, pain/discomfort, and anxiety/depression. The VAS provides a direct valuation of the respondent's current state of health, whereas the descriptive system can be used as a health profile or converted into an index score representing a von Neumann-Morgenstern utility value for current health [9]. The level of problem reported on each of the EQ-5D dimensions determines a unique health state. Health states are converted into a weighted health state index by applying scores from the EQ-5D preference weights elicited from general population samples. These weights lie on a scale on which full health has a value of 1 and dead a value of 0 . For this study, U.S. population weights were used to convert to an EQ-5D index score [14].

\section{Statistical analysis}

For each group (type 2 diabetes, high risk and low risk), the mean EQ-5D scores both overall and by dimension are reported. Statistical comparisons across groups (with emphasis on comparisons between the type 2 diabetes group and the other groups) were performed using analysis of variance with Fisher's least significant difference post-hoc testing, with $p<0.01$ considered significant.

In addition, multivariable linear regression modeling was used to identify those factors that most affected respondents' EQ-5D scores, including the diabetes risk group (type 2 diabetes, high risk or low risk). Even though the EQ-5D is a 5-item scale, linear regression modeling has been used in previous HRQoL studies. These investigations have demonstrated the comparability of EQ-5D 
with other generic HRQoL instruments and its usefulness in identifying determinants of health states [15-17]. The following sociodemographic factors were included: age, gender, race, geographic region, household income and size, BMI category, and group status (low risk, high risk, or type 2 diabetes) to determine if diabetes risk was independently associated with HRQoL after adjusting for the sociodemographic characteristics as well as assessing if the sociodemographic factors were independently associated with HRQoL. The sociodemographic categories are those used by the U.S. Census Bureau to describe the U.S. population and are utilized in SHIELD to demonstrate the representativeness of the study sample. Reference categories were selected as the largest group except for income (highest category) and diabetes risk status (type 2 diabetes). Using the methodology of Cavrini and associates and Sitoh and colleagues $[18,19]$, an ordinal variable for the EQ-5D index was created by categorizing the continuous variable into 4 levels, and an ordered logit regression model was used to confirm the multivariate linear regression. Results were similar between the linear and ordered regressions, so the linear regression results were presented since this statistical technique is more widely used.

\section{Results}

Of the 22,001 baseline survey questionnaires mailed, 17,640 were returned (response rate: $80.2 \%$ ). Complete responses for the EQ-5D were available from $>75 \%$ of each cohort $(5,639$ of 7,403 for low risk, 5,370 of 6,742 for high risk, and 3,849 of 5,000 for type 2 diabetes). The sociodemographic characteristics of the baseline respondents who completed the EQ-5D in each group are shown in Table 1. The low- and high-risk groups had a significantly greater proportion of respondents who were younger, white, and had more education and higher income compared with the type 2 diabetes group, $\mathrm{p}<$ 0.01 .

\section{VAS state of health}

Mean EQ-5D VAS scores were significantly higher for lowand high-risk respondents (79.6 and 70.4, respectively) compared with type 2 diabetes respondents $(66.8, p<$ 0.001 for each) (Figure 1). In addition, the mean VAS score for low-risk respondents was significantly higher than the mean score for the high-risk group $(p<0.001)$. A greater proportion (34.5\%) of respondents at low risk for diabetes rated their current state of health $>90$ on the VAS, compared with respondents with type 2 diabetes (13.9\%) or at high risk for diabetes $(17.7 \%)$.

\section{Utility index scores}

The pattern of EQ-5D utility index scores was similar to that observed for VAS scores (Figure 2). Mean EQ-5D index scores were significantly higher for low- and highrisk respondents ( 0.870 and 0.792 , respectively) than for those with type 2 diabetes $(0.778, p<0.001$ for each). The mean index score for low-risk respondents was significantly higher than the mean for the high-risk group ( $p<$ $0.001)$.

\section{EQ-5D dimensions}

Examination of each of the 5 dimensions of the EQ-5D showed similar rating scores for the type 2 diabetes and high-risk groups, with both groups more likely to report more difficulties or limitations compared with the lowrisk group (Table 2). A much higher proportion of respondents with type 2 diabetes $(47.9 \%)$ and those at high risk $(43.4 \%)$ reported having mobility problems compared with those at low risk $(17.1 \%)(p<0.001$ for both) (Table 2). Percentages of respondents reporting problems with self-care were generally low across all groups; however, respondents with type 2 diabetes (8.5\%) or at high risk (6.5\%) were more likely to report this problem compared with those at low risk (2.7\%). More than twice as many respondents with type 2 diabetes (36.1\%) and those at high risk (33.3\%) reported having problems performing usual activities compared with those at low risk $(15.7 \%)(p<0.001)$. More respondents with type 2

Table I: Characteristics of SHIELD baseline respondents who completed the EQ-5D, by group

\begin{tabular}{|c|c|c|c|}
\hline Characteristics & Low Risk $n=5,639$ & High Risk $n=5,370$ & Type 2 Diabetes $n=3,849$ \\
\hline Age, mean, yrs (SD) & $47.0(16.4)^{*}$ & $58.9(\mid 4.6)^{*}$ & $60.3(13.1)$ \\
\hline Women, \% & $65.5 \% *$ & $56.6 \%$ & $57.8 \%$ \\
\hline Race, \% white & $88.3 \% *$ & $88.4 \% *$ & $85.0 \%$ \\
\hline Education, \% with some college or higher & $74.0 \% *$ & $67.3 \% *$ & $63.9 \%$ \\
\hline Income, $\%$ with $<\$ 40,000 /$ year & $36.5 \% *$ & $46.3 \% *$ & $52.5 \%$ \\
\hline \multicolumn{4}{|l|}{ Geographic region, \% } \\
\hline Northeast & $18.8 \%$ & $19.7 \%$ & $19.9 \%$ \\
\hline South & $34.2 \%$ & $36.7 \%$ & $38.5 \%$ \\
\hline Midwest & $25.5 \%$ & $25.5 \%$ & $23.5 \%$ \\
\hline West & $21.4 \%$ & $18.1 \%$ & $18.0 \%$ \\
\hline
\end{tabular}

\footnotetext{
$* p<0.01$ for comparison with type 2 diabetes
} 


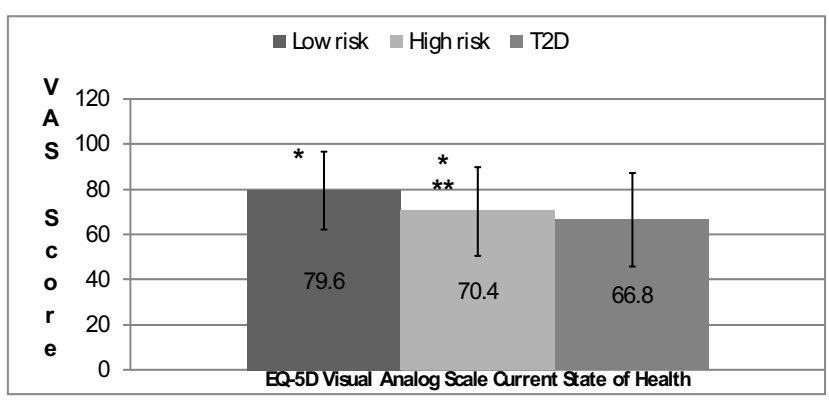

\section{Figure I}

Mean EQ-5D VAS scores by group. ${ }^{*} p<0.00$ I, low risk versus T2D and low risk versus high risk. **p $<0.001$, high risk versus T2D. EQ-5D = EuroQoL- 5 Dimensions; T2D = type 2 diabetes.

diabetes (61.1\%) and at high risk (61.8\%) reported experiencing some pain or discomfort compared with those at low risk $(43.5 \%)(p<0.001)$. Additionally, a greater proportion of those with type 2 diabetes $(10.5 \%)$ and those at high risk $(9.4 \%)$ reported extreme pain or discomfort compared with low-risk respondents $(4.2 \%)(p<0.001)$. The proportion of respondents reporting moderate levels of anxiety or depression was similar across respondents with type 2 diabetes (26.1\%) and at high risk (24.9\%), and lowest in respondents at low risk for diabetes (19.9\%).

\section{Multivariable linear regression models}

Diabetes risk status was significantly associated with HRQoL after adjusting for sociodemographic factors (Table 3). Compared with type 2 diabetes respondents, the low-risk respondents (9.02 for VAS score and 0.049 for index score; $\mathrm{p}<0.0001)$ and high-risk respondents (3.18 for VAS score and 0.009 for index score; $p=0.008$ ) reported higher EQ-5D scores. The model F statistic was 94.0 for VAS score and 83.6 for index score, and the model r-square was 0.16 for VAS score and 0.15 for index score.

Other sociodemographic characteristics were significantly associated with EQ-5D scores upon adjusting for diabetes risk status, including age, income, obesity, gender, race, geographic region, and household size (Table 3 ). Increas-

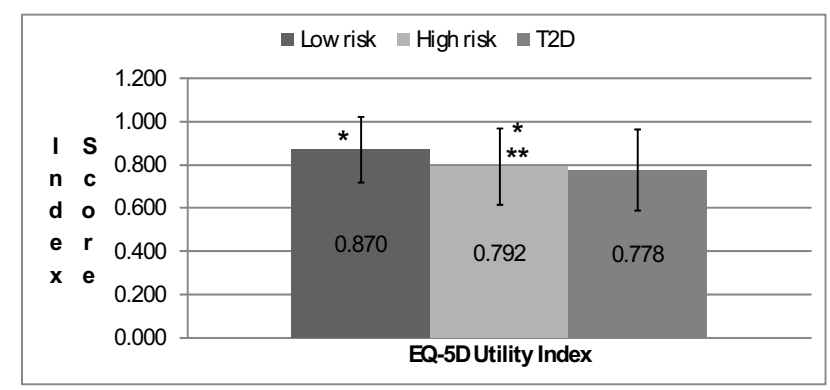

\section{Figure 2}

Mean EQ-5D utility index scores by group. ${ }^{*} p<0.00$ I, low risk versus T2D and low risk versus high risk. **p $<$ 0.001 , high risk versus T2D. EQ-5D = EuroQoL- 5 Dimensions; T2D = type 2 diabetes.

ing age was associated with decreased quality of life for EQ-5D index scores, although not for VAS scores. Respondents aged 55-64 years or 75 years and older reported the greatest negative impact on quality of life ( $p$ $<0.001$ vs. respondents aged 35-44 years), with those aged 18-24 years having the highest EQ-5D scores. The analysis of VAS scores for current health state showed no clear trend across age groups compared with respondents aged 35-44 years. For both VAS and index scores, respondents' HRQoL decreased as household incomes decreased; those with incomes $<\$ 22,500$ reported the greatest negative impact on HRQoL $(p<0.001$ vs. $\geq \$ 90,000$ in both models).

For both EQ-5D scores, obesity (BMI $\geq 28 \mathrm{~kg} / \mathrm{m}^{2}$ ) was associated with significantly lower HRQoL ( $\mathrm{p}<0.0001)$, while black race was associated with significantly higher HRQoL compared with white race $(\mathrm{p}<0.05)$ (Table 3$)$. The results for other sociodemographic factors indicate that female gender and household size of 3 or $\geq 5$ were associated with a negative impact on EQ-5D VAS scores, and female gender and a household size $\geq 2$ were associated with a negative impact on EQ-5D index scores. HRQoL was significantly higher among residents of other geographic regions compared with the Pacific region for both EQ-5D scores.

Table 2: Proportion of respondents reporting problems on each EQ-5D dimension in the baseline SHIELD survey, by group

\begin{tabular}{|c|c|c|c|}
\hline Proportion of respondents reporting some or unable, or moderately/extremely, \% & Low risk & High risk & Type 2 Diabetes \\
\hline Decreased mobility & $17 . I^{* \Lambda}$ & $43.4^{*}$ & 47.9 \\
\hline Difficulty with self-care & $2.7^{* \wedge}$ & $6.5^{*}$ & 8.5 \\
\hline Problems performing usual activities & $15.7^{* \Lambda}$ & $33.3^{*}$ & 36.1 \\
\hline Pain or discomfort & $43.5^{* \wedge}$ & 61.8 & 61.1 \\
\hline Anxious or depressed & $19.9 * \Lambda$ & 24.9 & 26.1 \\
\hline
\end{tabular}

EQ-5D = EuroQoL-5 Dimensions; ${ }^{*} p<0.001$ for comparison with type 2 diabetes; ${ }^{\wedge} p<0.000$ I for comparison of high risk to low risk 
Table 3: Multivariable linear regression analyses of factors impacting EQ-5D scores in SHIELD baseline respondents*

\begin{tabular}{|c|c|c|c|c|c|}
\hline \multirow[t]{2}{*}{ Variables } & & \multicolumn{2}{|c|}{ EQ-5D VAS score $n=14,383$} & \multicolumn{2}{|c|}{ EQ-5D index score $n=\mid 4,378$} \\
\hline & & Beta coefficient & SE & Beta coefficient & SE \\
\hline \multicolumn{6}{|c|}{ Diabetes risk group } \\
\hline & Low risk & $9.02 \dagger$ & 0.45 & $0.049 \dagger$ & 0.004 \\
\hline & High risk & $3.18 \dagger$ & 0.39 & $0.009 \dagger$ & 0.004 \\
\hline & Type 2 diabetes & (reference) & & (reference) & \\
\hline \multicolumn{6}{|l|}{ Age (yrs) } \\
\hline & $18-24$ & $5.69 \dagger$ & 0.94 & $0.052 \dagger$ & 0.008 \\
\hline & $25-34$ & 0.39 & 0.63 & 0.011 & 0.006 \\
\hline & $35-44$ & (reference) & & (reference) & \\
\hline & $45-54$ & -0.65 & 0.51 & $-0.025 t$ & 0.005 \\
\hline & $55-64$ & -0.34 & 0.54 & $-0.033 \dagger$ & 0.005 \\
\hline & $65-74$ & $2.82 \dagger$ & 0.58 & $-0.011+$ & 0.005 \\
\hline & $\geq 75$ & -0.45 & 0.64 & $-0.031 \dagger$ & 0.006 \\
\hline \multicolumn{6}{|l|}{ Gender } \\
\hline & Female & $-1.16 \dagger$ & 0.32 & $-0.029 \dagger$ & 0.003 \\
\hline & Male & (reference) & & (reference) & \\
\hline \multicolumn{6}{|l|}{ Race } \\
\hline & White & (reference) & & (reference) & \\
\hline & Black & $1.20 \dagger$ & 0.59 & $0.014 \dagger$ & 0.005 \\
\hline & Other & -1.66 & 0.96 & -0.015 & 0.009 \\
\hline \multicolumn{6}{|c|}{ Household Income $(\$)$ per year } \\
\hline & $<22,500$ & $-13.03 \dagger$ & 0.49 & $-0.121 \dagger$ & 0.004 \\
\hline & $22,500-39,999$ & $-6.68 t$ & 0.49 & $-0.066 t$ & 0.004 \\
\hline & $40,000-59,999$ & $-3.62 \dagger$ & 0.50 & $-0.037 \dagger$ & 0.004 \\
\hline & $60,000-89,999$ & $-1.71 \dagger$ & 0.49 & $-0.020 \dagger$ & 0.004 \\
\hline & $\geq 90,000$ & (reference) & & (reference) & \\
\hline \multicolumn{6}{|c|}{ Geographic region } \\
\hline & Northeast & $2.70 \dagger$ & 0.80 & $0.029 \dagger$ & 0.007 \\
\hline & Middle Atlantic & $2.34 \dagger$ & 0.58 & $0.026 \dagger$ & 0.005 \\
\hline & East North Central & $2.28 \dagger$ & 0.56 & $0.021 \dagger$ & 0.005 \\
\hline & West North Central & $2.58 \dagger$ & 0.70 & $0.023 \dagger$ & 0.006 \\
\hline & South Atlantic & $1.87 \dagger$ & 0.54 & $0.015 \dagger$ & 0.005 \\
\hline & East South Central & 0.42 & 0.73 & -0.002 & 0.007 \\
\hline & West South Central & $1.75 \dagger$ & 0.63 & $0.014 \dagger$ & 0.006 \\
\hline & Mountain & 1.03 & 0.74 & 0.011 & 0.007 \\
\hline & Pacific & (reference) & & (reference) & \\
\hline \multicolumn{6}{|c|}{ Household size (no. of members) } \\
\hline & 1 & (reference) & & (reference) & \\
\hline & 2 & -0.77 & 0.43 & $-0.009 \dagger$ & 0.004 \\
\hline & 3 & $-1.68 \dagger$ & 0.53 & $-0.018 \dagger$ & 0.005 \\
\hline & 4 & -1.05 & 0.59 & $-0.010 \dagger$ & 0.005 \\
\hline & $\geq 5$ & $-2.52 \dagger$ & 0.64 & $-0.022 \dagger$ & 0.006 \\
\hline \multicolumn{6}{|c|}{ Body mass index $\left(\mathrm{kg} / \mathrm{m}^{2}\right)$ group } \\
\hline & Underweight & $-3.12 \dagger$ & 1.43 & -0.017 & 0.013 \\
\hline & Normal weight & (reference) & & (reference) & \\
\hline & Overweight & $-1.33 \dagger$ & 0.46 & -0.007 & 0.004 \\
\hline & Obese & $-6.57 \dagger$ & 0.47 & $-0.047 \dagger$ & 0.004 \\
\hline
\end{tabular}

*Scores indicate change from reference group. $t p<0.05$ versus reference group EQ-5D = EuroQoL-5 Dimensions; VAS = visual analog scale; $\mathrm{SE}=$ standard error

\section{Discussion}

The EQ-5D results from the SHIELD survey demonstrate that respondents at low risk for the development and diagnosis of diabetes experienced the lowest proportion of self-reported difficulties in all 5 measured dimensions (mobility, self-care, usual activities, pain/discomfort, and anxiety/depression) compared with respondents with type 2 diabetes or at high cardiometabolic risk. Overall EQ-5D scores, whether measured by VAS or index score, were substantially higher in the low-risk group compared with the high-risk and type 2 diabetes groups, even after adjusting for sociodemographic characteristics. The high- 
risk and type 2 diabetes groups had similar health profiles and overall scores, although the latter reported somewhat lower overall HRQoL.

Respondents with type 2 diabetes reported the highest rates of difficulties with mobility, self-care, and performing usual activities. Similar proportions $(>60 \%)$ of respondents with type 2 diabetes and at high risk for diabetes reported experiencing some pain or discomfort. Reported rates of moderate anxiety or depression were also similar for respondents with type 2 diabetes and those at high risk. These findings were similar to other studies, which found impaired physical and social functioning as measured by the SF-36 among individuals with type 2 diabetes $[20,21]$.

This study provides evidence of the HRQoL of respondents at risk for diabetes as well as those with type 2 diabetes using a generic HRQoL instrument. The EQ-5D in the present study allowed for comparisons of respondents not yet diagnosed with diabetes since the dimensions were relevant to overall well-being. Other studies have typically compared type 2 diabetes patients with the general population [20-22]. Studies using the Medical Expenditure Panel survey (MEPS) examined individual risk factors and a cluster of similar cardiometabolic risk factors (BMI $\geq 25$ or $\geq 30 \mathrm{~kg} / \mathrm{m}^{2}$, hyperlipidemia, hypertension and diabetes) as used in the present study and found a similar significant deleterious impact on HRQoL as measured by the EQ-5D and SF-36 [22,24].

Construct validity of the EQ-5D has been established in several chronic diseases, including rheumatoid arthritis $[25,26]$, stroke [27], and AIDS [28]. However, it has not been widely used in diabetes studies, where preference is to use the various disease-specific HRQoL instruments. Yet, the EQ-5D is a valid measure of HRQoL with modest correlation with measures of impairment (e.g., joint scores, HIV scales) and high correlation with patients' perception of their disabilities (e.g., Health Assessment Questionnaire, Barthel Index, and Modified Rankin scale) $[25,27,28]$. The EQ-5D has performed equally well when compared with other generic HRQoL and utility-based instruments, including the Health Utilities Index Mark 2 and 3 and SF-6D $[26,29]$.

In the present study, no clear trend in the EQ-5D VAS scores across age groups was observed, even though there was a strong age association in the EQ-5D index score. In rheumatoid arthritis, Hurst and colleagues [25] found a negative association with age for both the utility and VAS scores; yet Hart and colleagues [17] found no age association among patients with type 1 diabetes mellitus. It is unclear in the present study why current health status
(VAS) was reported as better in 65-74-year-old respondents compared with 35-44-year-old respondents.

The EQ-5D utility scores from this study provide a preference-based score that can be used to calculate qualityadjusted life years for future cost-effectiveness analyses of treatment or prevention of diabetes and evaluating healthcare interventions both clinically and economically. Since SHIELD respondents are representative of the U.S. population with or at risk for diabetes, the EQ-5D utility scores would be useful for national and multinational comparisons for quality-adjusted life-year assessments.

The present study provides evidence of the impact of type 2 diabetes and high risk on HRQoL in a large sample with a high survey response rate. Moreover, the respondents are representative of the U.S. population, and the evaluation of HRQoL was done using a standardized, validated measure so that norm-based results are provided. However, it should be noted that household panels such as those used for this survey tend to under-represent the very wealthy and very poor segments of the population, and do not include military or institutionalized individuals. In addition, SHIELD relied only on self-reported data to identify samples of respondents, without clinical or laboratory confirmation. These limitations are the same for most survey-based methodologies.

\section{Conclusion}

The EQ-5D results from the SHIELD survey show that respondents with type 2 diabetes and those at high risk for future diagnosis of diabetes report decreased overall HRQoL and more difficulty with mobility, self-care, and usual activities compared with those at lower risk. Reported reductions in HRQoL may be due to related comorbidities or to overall health burden. Reducing cardiometabolic risk factors may lead to significant improvements in HRQoL even before diabetes is diagnosed in high-risk respondents. Respondents with a low risk for diabetes consistently reported the lowest rates of problems or difficulties across all 5 health dimensions measured by the EQ-5D. Further follow-up is needed to track HRQoL profiles over time, as those who are at risk for diabetes are diagnosed and learn to cope with their disease.

\section{Abbreviations}

BMI - Body mass index; EQ-5D - EuroQoL-5 Dimensions; HRQoL - Health-related quality of life; RF - Risk factor; SHIELD - Study to Help Improve Early evaluation and management of risk factors Leading to Diabetes; U.S. - United States; VAS - Visual analog scale 


\section{Competing interests}

SHIELD, the SHIELD Study Group, and the preparation of this manuscript were supported by funding from AstraZeneca LP. Dr. Susan Grandy is an employee of AstraZeneca LP, and Dr. Fox is a research consultant for AstraZeneca LP.

\section{Authors' contributions}

SG participated in the conception, design and coordination of the SHIELD study and helped to draft the manuscript. KF performed the statistical analysis and drafted the manuscript. All authors read and approved the final manuscript.

\section{Acknowledgements}

The SHIELD Study Group includes the following individuals: Harold E. Bays, MD (chair), Debbra D. Bazata, RD, LD, MA, Nathaniel G. Clark, MD,

Andrew J. Green, MD, Sandra J. Lewis, MD, Helena Rodbard, MD, Michael L. Reed, PhD, and Walter Stewart, PhD. The following individuals also contributed to the work reported in this manuscript: Richard Chapman (analysis and manuscript drafting) of ValueMedics Research; and Tina Fanning (data collection and analysis) of Vedanta Research. This study was presented as a poster at the ISPOR $12^{\text {th }}$ Annual International Meeting, Arlington, VA, May 19-23, 2007.

\section{References}

I. Centers for Disease Control and Prevention: National diabetes fact sheet: general information and national estimates on diabetes in the United States, 2005. Atlanta, GA: U.S. Department of Health and Human Services, Centers for Disease Control and Prevention 2005.

2. American Diabetes Association: Complication of diabetes in the United States. [http://www.diabetes.org/diabetes-statistics/com plications.jsp]. Accessed May 4, 2007

3. Thom T, Haase N, Rosamond W, Howard VJ, Rumsfeld J, Manolio T, Zheng Z], Flegal K, O'Donnell C, Kittner S, Lloyd-Jones D, Goff DC Jr, Hong Y, Adams R, Friday G, Furie K, Gorelick P, Kissela B, Marler J, Meigs J, Roger V, Sidney S, Sorlie P, Steinberger J, WasserthielSmoller S, Wilson M, Wolf P, American Heart Association Statistics Committee and Stroke Statistics Subcommittee: Heart disease and stroke statistics - 2006 update: a report from the American Heart Association Statistics Committee and Stroke Statistics Subcommitee. Circulation 2006, I I 3:e85-e I 5 I.

4. Luscombe FA: Health-related quality of life measurement in type 2 diabetes. Value Health 2000, 3(Suppl I): I5-28.

5. Garratt AM, Schmidt L, Fitzpatrick R: Patient-assisted health outcome measures for diabetes: A structured review. Diabet Med 2002, I9:I-II.

6. Watkins K, Connell CM: Measurement of health-related QOL in diabetes mellitus. Pharmacoeconomics 2004, 22: I 109-I I 26.

7. Centers for Disease Control and Prevention: Self-rated fair or poor health among adults with diabetes - United States, | 996-2005. MMWR 2006, 55: | 224- | 227.

8. Anderson RM, Fitzgerald JT, Wisdom K, Davis WK, Hiss RG: A comparison of global versus disease-specific quality-of-life measures in patients with NIDDM. Diabetes Care 1997, 20:299-305.

9. Rabin R, de Charro F: EQ-5D: a measure of health status from the EuroQol Group. Ann Med 200I, 33:337-343.

10. Bays HE, Chapman RH, Grandy S, the SHIELD Investigators' Group: The relationship of body mass index to diabetes mellitus, hypertension and dyslipidaemia: comparison of data from two national surveys. Int J Clin Pract 2007, 6 I:737-747.

II. American Diabetes Association: Standards of Medical Care in Diabetes - 2007. Diabetes Care 2007, 30(SuppI I):S4-S4I.

12. National Cholesterol Education Panel (NCEP); National Heart, Lung and Blood Institute: Detection, evaluation and treatment of high blood cholesterol in adults (Adult Treatment Panel III).
Final Report. 2002 [http://www.nhlbi.nih.gov/guidelines/choles terol/atp3 rpt.htm]. Accessed May 4, 2007

13. EuroQoL Group: EuroQol - a new facility for the measurement of health-related quality of life. Health Policy 1990, 1 6:199-208.

14. Shaw JW, Johnson JA, Coons SJ: US valuation of the EQ-5D health states: Development and testing of the $D I$ valuation model. Med Care 2005, 43:203-220.

15. Sapin C, Fantino B, Nowicki M, Kind P: Usefulness of EQ-5D in assessing health status in primary care patients with major depressive disorder. Health and Quality of Life Outcomes 2004, 2:20.

16. Kind $\mathrm{P}$, Koltowska-Haggstrom $\mathrm{M}$ : Incorporating social preferences in the measurement of QoL outcomes in growth hormone deficiency (GHD) in adults. Endocrine Abstracts 2004, 7:PI47.

17. Hart HE, Redekop WK, Bilo HJG, Meyboom B, Berg M: Health related quality of life in patients with type I diabetes mellitus: generic and disease-specific measurement. Indian J Med Res 2007, I 25:203-2 I6.

18. Cavrini G, Pacelli B, Pandolfi P, Collina N, Mezzetti F, Pesci P, Perlangeli $V$ : A proposal for modeling an EQ-5D index by ordered regression model. University of Bologna, Italy 2004.

19. Sitoh YY, Lau TC, Zochling J, Schwarz J, Chen JS, March LM, Cumming RG, Lord SR, Sambrook PN, Cameron ID: Determinants of health-related quality of life in institutionalized older persons in northern Sydney. Internal Med J 2005, 35: | 3 |- | 34.

20. Hanninen J, Takala J, Keinanen-Kiukaanniemi S: Quality of life in NIDDM patients assessed with the SF-20 questionnaire. Diabetes Res Clin Pract 1998, 42:17-27.

21. Schlotz W, Ambery P, Syddall HE, Crozier SR, Sayer AA, Cooper C, Phillips DI, Hertfordshire Cohort Study Group: Specific associations of insulin resistance with impaired health-related quality of life in the Hertfordshire Cohort Study. Qual Life Res 2007, 1 6:429-436.

22. Ribu L, Hanestad BR, Moum T, Birkeland K, Rustoen T: A comparison of the health-related quality of life in patients with diabetic foot ulcers, with a diabetes group and a nondiabetes group from the general population. Qual Life Res 2007, 26:179-189.

23. Sullivan PW, Ghushchyan V, Wyatt HR, Wu EQ, Hill JO: Impact of cardiometabolic risk factor clusters on health-related quality of life in the U.S. Obesity 2007, I 5:51 I-52 I.

24. Sullivan PW, Lawrence WF Jr, Ghushchyan V: A national catalogue of preference-based scores for chronic conditions in the U.S. Med Care 2005, 43:736-749.

25. Hurst NP, Kind P, Ruta D, Hunter M, Stubbings A: Measuring health-related quality of life in rheumatoid arthritis: validity, responsiveness and reliability of EUROQOL (EQ-5D). Brit J Rheumatol 1997, 36:55।-559.

26. Luo N, Chew LH, Fong KY, Koh DR, Ng SC, Yoon KH, Vasoo S, Li SC, Thumboo J: A comparison of the EuroQol-5D and the Health Utilities Index mark 3 in patients with rheumatic disease. J Rheumatol 2003, 30:2268-2274.

27. Pickard AS, Johnson JA, Feeny DH: Responsiveness of generic health-related quality of life measures in stroke. Qual Life Res 2005, 14:207-219.

28. Wu AW, Jacobson KL, Frick KD, Clark R, Revicki DA, Freedberg KA, Scott-Lennox J, Feinberg J: Validity and responsiveness of the euroqol as a measure of health-related quality of life in people enrolled in an AIDS clinical trial. Qual Life Res 2002, I I :273-282

29. Wee HL, Machlin D, Loke WC, Li SC, Cheung YB, Luo N, Feeny D, Fong KY, Thumboo J: Assessing differences in utility scores: a comparison of four widely used preference-based instruments. Value Health 2007, 10:256-265. 